\title{
Maternal Knowledge and Practice Regarding Children's Nutrition and Impact on Growth of their Children in Sixth of October City, Cairo. ${ }^{1}$ Ayat F. Manzour, ${ }^{2}$ Randa. M. Assalya and ${ }^{3}$ Amel. A. EL Faramawy
}

${ }^{1}$ Community, environmental \& occupational medicine department, Faculty of Medicine Ain Shams University - Cairo, Egypt, ${ }^{2}$ Faculty of Medicine - Abu Dees University Palestine, ${ }^{3}$ Pediatrics Department, Faculty of Medicine - Ain Shams University - Cairo, Egypt.

Received: August, 2018 Accepted: October, 2018

\section{Abstract:}

Background: Malnutrition has been responsible for $60 \%$ of the 10.9 million annual deaths and 50 to $70 \%$ of the burden of diarrheal disease and respiratory tract infections among under-five year's old children. It is also a major cause of disability preventing children from reaching their full developmental potential. In the context of nutrition and food consumption; knowledge is generally defined as the understanding of the health benefits of different foods and nutrients. This awareness of healthy nutrition is then translated to feeding practice. Objectives: To assess mothers' feeding knowledge and practice of their 6 to 60 months old children in $6^{\text {th }}$ of October City and to evaluate the influence of this knowledge on their children's nutritional status. Method: A cross-sectional study was conducted among mothers-children pairs randomly selected from two family health centers in $6^{\text {th }}$ of October city using an interview questionnaire, $24 \mathrm{hr}$. dietary recall, and anthropometric measurements. Results: Interviewed participants were 252; mean mothers' age was $27.9 \pm 6$ years, $81 \%$ were housewives, and $61 \%$ had higher than $2^{\text {ry }}$ school education. Early initiation of breastfeeding (BF) was reported by $28.9 \%$ of mothers, $51.2 \%$ practiced exclusive BF for 4-6 months, 25.4\% gave formula milk during 1st 6 month of life, $16.4 \%$ continued breast feeding up to 2 years. Stunting, wasting \& overweight among children were $20.2 \%, 6 \%$ and $9.9 \%$ respectively. Mother`s age, education, nutritional knowledge and practice scores, and family socioeconomic status significantly affected child`s Height for age Z-score (HAZ) and Weight for Height Z-score (WHZ). Conclusion: This study demonstrated that mothers had good knowledge and practice regarding most aspects of BF and weaning yet they showed poor practice of early initiation and continuation of $\mathrm{BF}$, introduction of meat and whole eggs, child`s consumption of fruits, vegetables, and eggs.

Keywords: Nutrition, Knowledge, Practice, Preschool.

Corresponding author: Ayat Farouk Manzour, Email:ayatfaroukm@yahoo.com, 01003339059

\section{Introduction:}

Sufficient nutrition during early childhood is necessary to the development of each child's full human potential. ${ }^{1}$ Nutrition in the first 1,000 days of life (during pregnancy and the first two years) is critical for child's growth and survival. ${ }^{2}$

In the context of nutrition and food consumption; knowledge is generally defined as the understanding of the health benefits of different foods and nutrients. According to the well-known Social cognitive theory, the likelihood of a child eating five portions of fruit and vegetables a day will be influenced by social factors (e.g. mother's views on healthy eating), and environmental factors (e.g. the availability of fruits and vegetables). ${ }^{3}$ The term "practice" is generally defined as the observable actions of a person that could affect his/her or others' nutrition, including 
eating, feeding, washing hands, cooking and buying foods. ${ }^{4}$

Inappropriate infant and young-child feeding practices "IYCF" add to the global burden of disease, including consequences such as blindness and mortality due to vitamin A deficiency, impaired psychomotor development due to iron deficiency anemia, irreversible brain damage as a consequence of iodine deficiency, as well as massive impact on morbidity and mortality of proteinenergy malnutrition. ${ }^{5}$

Preschool children depend on their caregivers to make selections about the types of foods and beverages offered, and also the frequency and size of portions eaten. ${ }^{6}$ Improvements in diets of infants and preschool children will depend upon improved caregiver choices. ${ }^{7}$

Studies of under-five child malnutrition in Egypt have not explored well the influence of maternal and socioeconomic characteristics within the WHO/UNICEF model explaining childhood malnutrition in developing countries. Accordingly, further research was needed to understand the influence of underlying factors determining the nutritional status of children in Egypt. ${ }^{8}$ Infant feeding practices are constantly changing, and little is known about knowledge and practice of Egyptian mothers regarding IYCF, especially in 6th of October city where no similar previous studies were done. That was the rational for our study.

Objectives: To assess mother`s knowledge and practice of about nutrition of their 6-60 months old children in $6^{\text {th }}$ of October City and to evaluate the influence of this knowledge on the nutritional status of those children.

\section{Method}

A cross sectional study was conducted on 6 - 60 months children and their mothers attending the targeted family health centers. If a mother has more than one child, the youngest was selected to participate for better mother's recall. Mothers of children who have any congenital malformations or chronic illnesses affecting growth were excluded from participation. Mothers-children pairs attending the well-baby clinic were selected from two family health centers in $6^{\text {th }}$ of October city (El-Hossary Family health center $[\mathrm{FHC}]$ and the $6^{\text {th }}$ District FHC). Data collection started from $1^{\text {st }}$ of June 2016 and continued for three months . The program power and sample size calculator was used based on $95 \%$ confidence interval and $90 \%$ power of the test, a prevalence of mother's knowledge -in Giza Governorateregarding exclusive breast-feeding $\{40 \%\}$ (7). Sample size was 250 participants. A total of 315 participants were invited to participate. Twenty five participants were included in the pilot sample to test the questionnaire (not included in results), 252 participants have completed the interview questionnaire and anthropometric measurements, with a response rate of $87 \%$. A systematic random sample was done to select the required sample size; A name list of PHC attendants was obtained in the morning then every $4^{\text {th }}$ patient was chosen . This process took place on 3 different days each week.

Study Tools: 1) Interview Questionnaire: Questionnaire was designed based on WHO/PAHO 2003 (9), WHO 2005 (10), WHO/UNICEF 2012 global strategy for "IYCF" (11), and [FAO KAP] modules for assessment of IYCF 2015 (12). Based on pilot study testing, questions were modified and adjusted to suite the Egyptian culture. (A) Personal and sociodemographic data section: consisted of 15 questions and included; residence, mother`s age , Number of children, child's age, sex, and birth order), mother`s and father`s education and profession, family income and Number of household members. (B) Mother's nutritional knowledge \&feeding practices section: includes 32 questions evaluating maternal

No. 2

April

2019 
Table (1): Different aspects of Breastfeeding and weaning practices among participating mothers.

\begin{tabular}{|c|c|}
\hline Item & $252(\%)$ \\
\hline Ever breastfeeding: & 246 (97.6) \\
\hline \multicolumn{2}{|l|}{ Breast feeding Initiation: $\quad(\mathrm{N}=\mathbf{2 4 6})$} \\
\hline - Within $1^{\text {st }}$ hour after birth & $71(28.9)$ \\
\hline - $>1^{\text {st }}$ hour of birth & $175(71.1)$ \\
\hline \multicolumn{2}{|l|}{ Received pre-lacteal feeds } \\
\hline \multicolumn{2}{|l|}{\begin{tabular}{|ll} 
Pre-lacteal feeds: & $(\mathrm{N}=185)$
\end{tabular}} \\
\hline - Sugar and water \&/or Herbal drinks & $173(93.5)$ \\
\hline - Formula milk & $12(6.5)$ \\
\hline Complementary feeding with formula milk during $1^{\text {st }} 6$ months & $64(25.4)$ \\
\hline Duration of Exclusive Breastfeeding: (mean \pm SD) in months) & $4.3 \pm 2.4$ \\
\hline - $<4$ months & $78(30.9)$ \\
\hline - 4-6 months & $129(51.2)$ \\
\hline - $>6$ months & $45(17.9)$ \\
\hline \multicolumn{2}{|l|}{ Timing for initiation of weaning**: } \\
\hline - $<4$ months & $38(15.1)$ \\
\hline - 4 to 6 months & $129(51.2)$ \\
\hline - $>6$ months & $85(33.7)$ \\
\hline \multicolumn{2}{|l|}{ Food consistency at beginning of weaning: } \\
\hline - Smoothly mashed form & $230(91.3)$ \\
\hline - Liquid juices & $15(6)$ \\
\hline - Roughly mashed form & $7(2.7)$ \\
\hline \multicolumn{2}{|l|}{ Introduction of meat "red or white" \& its products: } \\
\hline - 4-6 months & $4(1.6)$ \\
\hline - $>6-8$ months & $34(13.5)$ \\
\hline - $\quad>8-12$ months & $126(50)$ \\
\hline - >1 year & $88(34.9)$ \\
\hline \multicolumn{2}{|l|}{ Introduction of whole eggs: $(\mathrm{N}=242)$} \\
\hline - 4-6 months & $10(4.1)$ \\
\hline - $>6-12$ months & $137(56.6)$ \\
\hline - $>1$ year & $95(39.3)$ \\
\hline \multicolumn{2}{|l|}{ Introduction of cow`s milk: } \\
\hline - Not introduced yet & $50(19.8)$ \\
\hline - $<12$ months & $46(18.3)$ \\
\hline - $>1$ year & $156(61.9)$ \\
\hline
\end{tabular}

$* E B F=$ Exclusive Breastfeeding; **Weaning is defined as introduction of semi solid and solid foods excluding formula milk; *** Mothers were allowed to choose more than one food item.

knowledge regarding breastfeeding, weaning, dietary supplements, introduction of essential foods, food groups, healthy and unhealthy nutritional habits, Iron deficiency anemia, feeding during gastroenteritis ...etc. Practice section includes 25 questions evaluating mothers practice regarding nutrition and feeding of their children (eg. breast-feeding, complementary feeding, weaning, introduction of essential foods, etc.)

1) 24 Hours Dietary Recall: This includes recalling and registering of all foods and beverages consumed by the child in the last 24 hours. This was used to calculate minimum meal frequency (MMF) which measures Proportion of children (breastfed or non-breastfed), who has received solid, semi-solid, or soft foods (also including milk feeds for non-breastfed children) the minimum number of times or more during the day. ${ }^{11}$ Minimum dietary diversity (MDD) which measures proportion of children who received foods from $\geq 4$ food groups of the WHO classified seven different

$\begin{array}{llll}\text { Vol. } 37 & \text { No. } 2 & \text { April } & 2019\end{array}$


food groups during the previous day by WHO/PAHO 2003 and WHO 2005. ${ }^{9,10}$

Table (2): Twenty four hours dietary recall of previous day as stated by participating mothers

\begin{tabular}{|l|l|}
\hline Variable & $252(\%)$ \\
\hline $\begin{array}{l}\text { Minimum Meal Frequency } \\
\text { according to child's age } \\
\text { (MMF): }\end{array}$ & $144(57.1)$ \\
Achieved & $108(42.9)$ \\
Not achieved & \\
\hline $\begin{array}{l}\text { Minimum Dietary Diversity } \\
\text { ( } 4 \text { dietary groups): }\end{array}$ & $153(60.7)$ \\
$\begin{array}{l}\text { Achieved } \\
\text { Not achieved }\end{array}$ & $99(39.3)$ \\
\hline
\end{tabular}

2) Anthropometric Measurements: Weight of the child was measured in kilograms using a digital bathroom scale to nearest 100 gram. Baby scale was used for children who were less than 2 years. Height/length: for infants; the recumbent length was measured while lying flat on an infant stadiometer with $0.5 \mathrm{~cm}$ precision. For children older than 2 years standing height was measured using a regular stadiometer, with $0.5 \mathrm{~cm}$ precision. (13) Then Body Mass Index: was calculated using the formula $\{\mathrm{BMI}=$ weight in $\mathrm{kg} /$ square the height in meters $\}$. These anthropometric indices were transformed into Z-scores using the software WHO Anthro version 3.2.2.

Ethical Considerations: Consent was obtained from mothers before starting interviews. Approval of the Research Ethics Committee (REC) in the Faculty of Medicine, Ain Shams University was obtained.

Data management: Data was coded, entered, and analyzed using Statistical Package for Social Sciences software (SPSS) version 20. Two point scale was used to rate mothers' knowledge which scored as $(1,0)$ for true and false respectively. A total knowledge score of 32 points was calculated for every participant .Maternal practice was judged upon based on WHO/PAHO 2003 and WHO 2005 recommendations (9) (10).
Mothers scored (0 or 1) for wrong and correct practices respectively.

Table (3): Effect of knowledge score and practice score on child's HAZ and child's WHZ

\begin{tabular}{|c|c|c|c|}
\hline & $\begin{array}{c}\text { Scores } \\
(\text { Mean } \pm \\
\text { SD) }\end{array}$ & Test & $P$ value \\
\hline $\begin{array}{l}\text { Knowledge } \\
\text { score } \\
\text { Stunting } \\
\text { Normal height }\end{array}$ & $\begin{array}{l}16.1 \pm 5.5 \\
19.3 \pm 5.6\end{array}$ & $\mathrm{t}=-3.7$ & $<0.001 *$ \\
\hline $\begin{array}{l}\text { Wasting } \\
\text { Normal weight } \\
\text { Overweight }\end{array}$ & $\begin{array}{c}13.9 \pm 3.2 \\
19.2 \pm 5.6 \\
17 \pm 6.1\end{array}$ & $\mathrm{~F}=7.39$ & $<0.001 *$ \\
\hline $\begin{array}{l}\text { Practice score } \\
\text { Stunting } \\
\text { Normal height }\end{array}$ & $\begin{array}{l}5.5 \pm 1.7 \\
8.2 \pm 2.1\end{array}$ & $t=-9.68$ & $<0.001 *$ \\
\hline $\begin{array}{l}\text { Wasting } \\
\text { Normal weight } \\
\text { Overweight }\end{array}$ & $\begin{array}{l}5.1 \pm 1.1 \\
8.1 \pm 2.1 \\
5.3 \pm 1.7\end{array}$ & $F=32.9$ & $<0.001 *$ \\
\hline
\end{tabular}

\section{Statistical Analysis:}

Description of data using (mean, standard deviation, and range) for quantitative data and (frequency, percentage) for qualitative data was done. Analysis of associations using student t-test and ANOVA test were done to compare quantitative variables .Chi Square was used to compare qualitative variables. $P$ value $<0.05$ was considered statistically significant. Bar charts were used to express some important percentages.

\section{Results:}

Nearly $55 \%$ of participating mothers came originally from urban residence, $81 \%$ were housewives, mean age $27.9 \pm$ 6. As regards educational level, $21 \%$ had a university degree, while $13.5 \%$ of them were illiterate or can only read and write. Number of household members ranged between 3 and 9 with a mean of $4.5 \pm 1.1$ persons. Participating Children aged between 7 to 59 months. Majority (59.9\%) aged between 24 months to 60 months, $47.2 \%$ were males. Out of 252 participating mothers $57.5 \%$ had one or two children, while only $2 \%$ had 5 or more children, $3.7 \%$ of children came as 
first child in the family, while $30.2 \%$

came as second child.

Table (4): Relationship between child's gender, maternal education and child's HAZ and child's WHZ

\begin{tabular}{|c|c|c|c|c|c|c|c|c|c|}
\hline \multirow[b]{2}{*}{ Exposure } & \multicolumn{4}{|l|}{ HAZ } & \multicolumn{5}{|l|}{ WHZ } \\
\hline & Stunting & Normal & $\chi_{2}$ & $\begin{array}{l}P \\
\text { value }\end{array}$ & Wasting & Normal & $\begin{array}{l}\text { Over- } \\
\text { weight }\end{array}$ & $\chi_{2}$ & $\begin{array}{l}P \\
\text { value }\end{array}$ \\
\hline \multicolumn{10}{|l|}{ Child`s Gender } \\
\hline \multirow[t]{2}{*}{ Male } & 20 & 99 & \multirow{4}{*}{1.65} & \multirow{4}{*}{0.20} & 10 & 92 & 17 & \multirow{4}{*}{7.85} & \multirow{4}{*}{$0.02^{*}$} \\
\hline & $39.2 \%$ & $49.3 \%$ & & & $66.7 \%$ & $43.4 \%$ & $68.0 \%$ & & \\
\hline \multirow[t]{2}{*}{ Female } & 31 & 102 & & & 5 & 120 & 8 & & \\
\hline & $60.8 \%$ & $50.7 \%$ & & & $33.3 \%$ & $56.6 \%$ & $32.0 \%$ & & \\
\hline \multicolumn{10}{|l|}{ Mother`s Education } \\
\hline \multirow[t]{2}{*}{ Illiterate /Reads \& writes } & 17 & 33 & \multirow{4}{*}{30.9} & \multirow{4}{*}{$\begin{array}{c}* * \\
0.00\end{array}$} & 7 & 38 & 5 & \multirow{4}{*}{20.5} & \multirow{4}{*}{$0.03^{*}$} \\
\hline & $33.3 \%$ & $16.4 \%$ & & & $46.7 \%$ & $17.9 \%$ & $20 \%$ & & \\
\hline \multirow[t]{2}{*}{ Primary School } & 9 & 15 & & & 3 & 18 & 3 & & \\
\hline & $17.6 \%$ & $7.5 \%$ & & & $20 \%$ & $8.5 \%$ & $12 \%$ & & \\
\hline \multirow[t]{2}{*}{ Preparatory School } & 1 & 21 & & & 0 & 20 & 2 & & \\
\hline & $2.0 \%$ & $10.4 \%$ & & & 0 & $9.4 \%$ & $8 \%$ & & \\
\hline \multirow[t]{2}{*}{ Secondary School } & 9 & 14 & & & 2 & 19 & 2 & & \\
\hline & $17.6 \%$ & $7.0 \%$ & & & $13.3 \%$ & $9 \%$ & $8 \%$ & & \\
\hline \multirow[t]{2}{*}{ Diploma } & 14 & 72 & & & 3 & 79 & 4 & & \\
\hline & $27.5 \%$ & $35.8 \%$ & & & $20 \%$ & $37.3 \%$ & $16 \%$ & & \\
\hline \multirow[t]{2}{*}{ University /Master degree } & 1 & 46 & & & 0 & 38 & 9 & & \\
\hline & $2.0 \%$ & $22.9 \%$ & & & 0 & $17.9 \%$ & $36 \%$ & & \\
\hline
\end{tabular}

Most of Participating mothers obtained their knowledge regarding child feeding from their acquaintances (67.5\%), from physicians $(62.3 \%)$, and from different media channels (42.9\%). The least reported source was nurses and midwives $(3.6 \%)$. Mean maternal knowledge score was $18.64 \pm 5.68$ (out of 32 points) while mean maternal practice score was $7.63 \pm 2.27$ (out

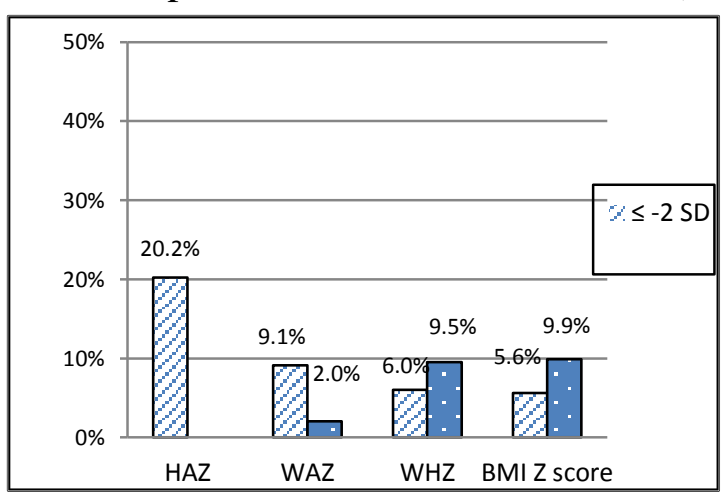

Figure (1): Percentage of consumption of the 7 WHO dietary groups by children during the day preceding interview

HAZ: Height for Age Z score, WAZ: Weight for Age $Z$ score, WHZ: Weight for Height Z score, BMIZ: BMI for Age Z score

of 16 points).

Current study found that $(97.6 \%)$ of participating mothers reported "ever- breastfeeding" their infants. About 29\% of reported early initiation within the first hour after birth . Majority (73.4\%) reported giving pre-lacteal feeds .One quarter $(25.4 \%)$ gave complementary formula feeding during first 6 months of infancy.

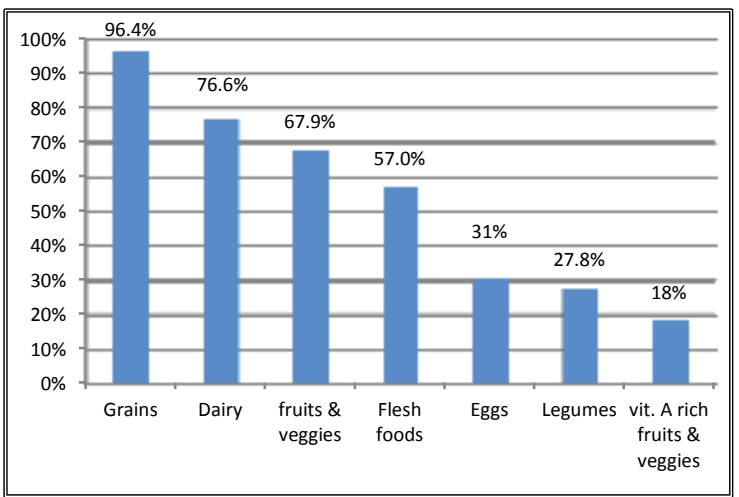

Figure (2): Anthropometric indices of participating children presented as $\mathrm{Z}$ scores.

Mean duration of exclusive breastfeeding (EBF) was $(4.3 \pm 2.4$ months $)$.Half $(51.2 \%)$ of lactating mothers practiced EBF for 4-6 months. Half of participating mothers $(51.2 \%)$ started weaning between 4-6 months of age. Most of participating mothers $(91.3 \%)$ prepared weaning foods in a smoothly mashed/grinded puree. Most of participating mothers $84.5 \%$ delayed introduction of meat products beyond the 
end of $8^{\text {th }}$ month of age, while $62 \%$ introduced cow`s milk beyond the child's first birthday (Table 1).

More than half $(57.1 \%)$ of participating children achieved the minimum meal frequency for their age and breastfeeding status as recommended. Also, more than half $(60.7 \%)$ of them fulfilled the minimum dietary diversity of $\geq 4$ dietary groups per day as recommended. (Table 2)

Most commonly consumed dietary group during previous day was grains $(96.4 \%)$. Only one third $(31 \%)$ of participating children consumed eggs during the previous day. Vitamin A rich fruits and vegetables, and legumes were the least consumed groups $(18 \%$ \& $27.8 \%$ respectively). (Figure 1)

Around one fifth of participating children (20.2\%) were stunted, $9.1 \%$ were underweight, and $6 \%$ were wasted. On the other hand $9.9 \%$ were overweight according to their BMI Z score, and 9.5\% according to their WHZ score. Figure (2) The occurrence of stunting, wasting, and underweight were higher among children aged 6-23 months than older children aged 24 to 60 months, while overweight was slightly higher among the older children (24 to 60 months old). Figure (3)

Mean of mothers' knowledge score was significantly lower among stunted children, compared to normal height

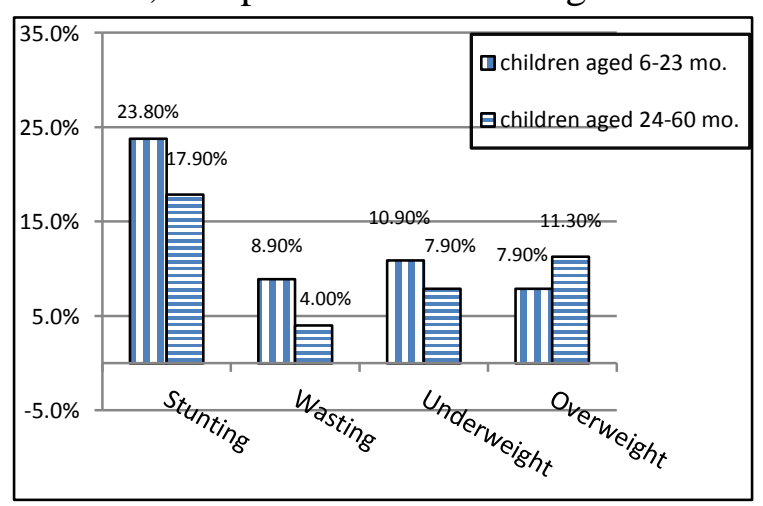

Figure (3): Percentage of abnormal growth indices $\mathrm{Z}$ scores of participating children in the two age groups children $(16.1 \pm 5.5)$ and $(19.3 \pm 5.6)$ respectively, among wasted children and overweight children, compared to children with normal body weight (13.9 $\pm 3.2),(17 \pm 6.1)$, and $(19.2 \pm 5.6)$ respectively. Mean of mother's practice score was significantly lower among stunted children $(5.5 \pm 1.7)$, compared to normal height children $(8.2 \pm 2.1)$, as well as when comparing wasted children $(5.1 \pm 1.1)$ and overweight children (5.3 \pm 1.7 ), to children with normal body weight (8.1 \pm 2.1$)$ Table (3)

Stunting and wasting were significantly higher among children of illiterate or reads \& writes only mothers $333.3 \%$ of stunted children compared to $16.4 \%$ with normal height, and $46.7 \%$ of wasting compared to $17.9 \%$ of children with normal weight). (Table 4)

Wasting and overweight were significantly higher among males $(66.7 \%$ of wasted and $68 \%$ of overweight children compared to $43.4 \%$ of normal weight children). Overweight was significantly higher among children of mothers with higher educational level (36\% of overweight children compared to $17.9 \%$ of normal weight children and $0 \%$ of wasted children).

Association between child's WHZ in relation to Number of children, mother's working status or child`s birth order was not statistically significant. Table (4)

\section{Discussion}

Participating mothers in this study reported gaining their knowledge regarding IYCF from their acquaintances $(67.5 \%)$, and physicians (62\%), which is similar to the results reported in an Ethiopian study ${ }^{14}$, declaring that $62 \%$ of Ethiopian mothers gained their feeding knowledge from physicians. Least reported source of knowledge in current study was nurses \& midwives in PHC (3.6\%) which differs from Iraqi mothers reported sources ${ }^{15}$, as PHC nurses came as most common source of knowledge $(55 \%)$, followed by physicians $(42 \%)$ 
and acquaintances (36\%). This can be explained by the poor role of PHC nurses and midwives illustrated in EDHS; $2014^{16}$, reporting that only $35 \%$ and $2.8 \%$ of Egyptian women had antenatal and postnatal care respectively delivered by PHC nurses and midwives. Current study showed that ever breastfeeding among participating mothers was $97.6 \%$, which agrees with EDHS; $2014^{16}$ and Khalaf Allah; $2014^{17}$ ever breastfeeding rates (96\% and $92 \%$ respectively). Early initiation of breastfeeding was found in only $28.9 \%$ of participating mothers who initiated $\mathrm{BF}$ within first hour after birth as recommended by WHO $2005^{10}$, WHO/UNICEF 2012 $2^{11}$, and baby friendly hospital initiative. This finding agrees with EDHS $2014^{16}$ in which $27 \%$ of Egyptian mothers initiated BF within the first hour after delivery. This finding is also similar rates of early initiation of BF in Arab countries like Saudi Arabia $(31 \%)^{18}$, Palestine $(24 \%)^{19}$, Jordan $(31 \%)^{20}$. This is inappropriate but widely accepted practice among Arab mothers might be contributed to cultural beliefs of women that breast-milk secretion is usually delayed. Ref

Regarding giving pre-lacteal feeds to infants, the majority of participating mothers $(73.4 \%)$ followed this poor but culturally encouraged practice. This is in concordance with EDHS 2014 ${ }^{16}$, as giving pre-lacteal feeds was reported by $62 \%$ of mothers. Also similar findings were demonstrated in a study on Lebanese mothers feeding practices ${ }^{21}$; as $80 \%$ of participating infants received prelacteal herbal drinks or sweetened water. Present study showed that $(51.2 \%)$ of participating mothers breastfed their infants exclusively for optimal duration as recommended. This rate of EBF for optimal duration agrees with Elsayed et al.; $2016^{22}$ study comparing optimal duration EBF practice of Egyptian versus Saudi mothers (65\% of Egyptian mothers compared to $14 \%$ of Saudi mothers).
This reflects an improvement of EBF practice than reported by EDHS $2014^{16}$; as only $13 \%$ and mean duration of EBF of 18 months. This improved practice could be due to what Egypt Nutrition Landscape Analysis Report 2012 23 declared; the availability of educational material for clients regarding the promotion of EBF was optimal (over $80 \%$ of family health centers in Egypt having educational materials on EBF).

Participating mothers demonstrated poor rate of continuation of breastfeeding, as $82.6 \%$ of mothers continued BF at age of one year as AAP recommends, while only $16.4 \%$ of them continued breastfeeding at age of 2 years or beyond as recommended by WHO/UNICEF. ${ }^{11}$ These rates are compatible with results of EDHS $2014^{16}$, which reported $\mathrm{BF}$ continuation at one year of $80 \%$ and of $20 \%$ at 2 years. Most common reported reasons for early cessation of $\mathrm{BF}$ included fatigue, mother's loss of desire to continue $\mathrm{BF}$, and pregnancy, which agrees with a study on infant feeding done in Palestine. $^{24}$ This demonstrates the importance of proper counseling, and continuous support provided to mothers to help them continue BF.

One quarter (25.4\%) of participating mothers gave complementary formula milk during first 6 months of life, which is also discouraged practice by WHO/UNICEF 2012. ${ }^{11}$ This rate agrees with UNICEF Annual Results Report; 2015 (25) which reported that mixed breast- and bottle-feeding as early as first month is commonly found in Middle East countries \& North Africa. It is also lower than the rate reported among Saudi mothers $^{18}$; as $91 \%$ of mothers in his study gave formula feeding in first six months of life. This can be explained as Al-Binali ${ }^{18}$ has explained; that Saudi mother`s feeding practice was affected by cultural factors like depending on nannies and baby sitters, and mothers' 
false perception of inadequacy of breastfeeding.

Majority of participating mothers $(84.9 \%)$ delayed introduction of all types of meat beyond $8^{\text {th }}$ months (WHO and AAP recommends meat products to be introduced by 6-8 months). At the same time, $60.7 \%$ of participating mothers introduced whole eggs too early to infants before age of one year which is also against WHO and AAP recommendations. Nevertheless, $62 \%$ of participating mothers introduced cow`s milk beyond first year as recommended.

Fifty seven percent of participating children achieved the minimum meal frequency for their age and breastfeeding status, and $61 \%$ achieved the minimum dietary diversity of 4 or more dietary groups per day as recommended by WHO/PAHO 2003 ${ }^{9}$, WHO $2005^{10}$, WHO/UNICEF 2012 (11). These percentages are similar to Egypt Nutrition Landscape Analysis Report; $2012^{23}$, and EDHS 2014 ${ }^{16}$, as the later reported that $60 \%$ achieved MMF and $43 \%$ achieved MDD among a random sample of 4744 preschool children.

Current study showed that $20.2 \%$ of participating children were stunted, $6 \%$ wasted, of $9.1 \%$ underweight and $9.9 \%$ overweight. The prevalence of malnutrition was close to results of EDHS; $2014^{16}$, (21.4\%), wasting was $8 \%$, and underweight was $6 \%$. Yet, prevalence of overweight was higher than current study (15\%). This may be explained that EDHS 2014 is a national survey including all different rural and urban governorates in Egypt with all different socio-cultural backgrounds. On the other hand, Khalaf Allah ${ }^{17}$ has reported a higher prevalence of stunting and underweight in her cross-sectional study $(32.6 \% \& 17.8 \%$ respectively), but this difference may be due to different populations as she studied 3-6 years old children in nurseries, Menufeya Governorate.
Current study showed positive association between mother's knowledge and practice regarding IYCF in relation to child's nutritional status (HAZ and WHZ) was also demonstrated by Mahfouz et al. in Giza governorate $2003^{26}$, and Seedhom et al $2014^{27}$ in Minia governorate. This association was explained by the UNICEF Nutrition Conceptual Framework for multidimensional etiology of malnutrition $^{28}$, which considered mother's education and nutritional knowledge one of the underlying causes affecting child`s nutritional status.

Study depended on information provided by mothers, thus, Recall bias was possible especially in the case of women with older children. In a trial to overcome this limitation, interviews mainly asked about major and memorable life events. Nevertheless, this study has shed more light on IYCF knowledge and practices of mothers in $6^{\text {th }}$ of October city-Egypt, and its association with nutritional status of their children.

\section{Ethical Considerations}

Consent was obtained from mothers before starting interviews. Approval of the Research Ethics Committee (REC) in the Faculty of Medicine, Ain Shams University was obtained before starting.

Study limitations: Associations drawn from cross sectional studies are inherently of limited accuracy. They need confirmatory case control or cohort studies. Current study sample may represent population who visit studied family health centers.

\section{Conclusion}

This study has demonstrated that mothers possessed good knowledge regarding most aspects of breastfeeding and weaning. Yet, they demonstrated poor knowledge regarding iron deficiency 
anemia, dietary groups and their roles. Participating mothers demonstrated good practice of ever-breastfeeding, EBF, and timing of initiation of weaning. On the contrary, they demonstrated poor practice of early initiation of $\mathrm{BF}$, giving prelacteal feeds, continuation of $\mathrm{BF}$ for 2 years, introduction of meat products and whole eggs, and child's consumption of meat products, fruits, vegetables, and eggs.

While indicators that affected children's nutritional status significantly included mother's education, knowledge and practice regarding IYCF.

\section{Recommendations}

The present study recommends encouraging and expanding the Baby friendly Hospital Initiative, and establishment of breastfeeding intervention programs for protection, promotion, and support of breastfeeding. The MOHP together with its partners must ensure that IYCF nutritional messages are featured regularly in different media platforms. Elimination of mother's illiteracy and encouraging higher education of girls and future mothers. Provision of skilled counselling and health education for mothers and pregnant women whenever possible (for ex. during visits to well-baby clinics, during immunization sessions, in- and out-patient visits, and reproductive health services), especially for younger and less educated mothers and among lower socioeconomic status families.

Conflicts of interest: none declared

\section{References:}

1. UNICEF , "UNICEF Annual Results Report 2014- Our Story"; 2015. ISBN: 97892-806-4809-6 Available from: http://www.unicef.org/publications/files/UNI CEF_Annual_Report_2014_Web_07June15. pdf

2. Kimani-Murage EW, Norris SA, Mutua MK, Wekesah F, Wanjohi M, Muhia N, et al.
Potential effectiveness of Community Health Strategy to promote exclusive breastfeeding in urban poor settings in Nairobi, Kenya: a quasi-experimental study. J Dev Orig Health Dis [Internet]. 2016 ;7(2):172-84. Available from:

http://www.journals.cambridge.org/abstract_ S2040174415007941

3. Roberts, K. \& Marvin, K. , "Knowledge and attitudes towards healthy eating and physical activity: what the data tell us Report", National Obesity Observatory, Oxford-England ;2011. Available at: http://www.noo.org.uk/uploads/doc/vid_111 71_Attitudes.pdf

4. May AL, Dietz WH. The Feeding Infants and Toddlers Study 2008: Opportunities to Assess Parental, Cultural, and Environmental Influences on Dietary Behaviors and Obesity Prevention among Young Children. J Am Diet Assoc, $2010 ; 110$ (12).

5. Contento, I.R. , "Nutrition education: linking research, theory and Practice", Asia Pac J Clin Nutr, 2008; Vol.17 No.1, pp.176179.

6. Victora, C.G., Bahl, R., Barros, A.G.D., Franca, G.V.A, Horton, S., Krasivic, J., et.al , "Breastfeeding in the 21st century: epidemiology, mechanisms, and lifelong effect", THE LANCET, 2016; Vol.387 No. 10017, pp. 475-549.

7. Hakim IA, El-Ashmawy IA. Breastfeeding patterns in a rural village in Giza, Egypt. Am J Public Health; (1992) ;82(5):731-2.

8. Zottarelli, L.K., Sunil, T.S. \& Rajaram, S., "Influence of parental and socioeconomic factors on stunting in children under 5 years in Egypt", EMHJ - Eastern Mediterranean Health Journal, 2007; Vol. 13 No.6, pp. 1330-1342.

9. WHO/PAHO, "Guiding principles for complementary feeding of the breastfed child", Pan American Health Organization, Washington DC- USA,2003;p 10:26.

10.Available at: http://www.who.int/ child_adolescent_health/documents/a85622/e n/index.html

11.WHO, "Guiding principles for feeding non-breastfed children 6-24 months of age", World Health Organization, GenevaSwitzerland ,2005; p 8:19. Available at: http://www.who.int/child_adolescent_health/ documents/9241593431/en/index.html
No. 2

April 2019 
12.WHOUNICEF,, "Global Strategy on Infant and Young Child Feeding", new edition, World Health Organization, GenevaSwitzerland,2012; p 9:13. Available at: 13.http://apps.who.int/iris/bitstream/10665/4 2590/1/9241562218.pdf

14.Macías YF \& Glasaue P, "Guidelines for assessing nutrition-related Knowledge, Attitudes and Practices manual" (eBook), Food and Agriculture Organization of the United Nations FAO ,Rome,2015. Available at: $\quad$ www.fao.org/docrep/019/i3545e/i3545 e00.html

15.Levine RS, Connor AM, Feltbower RG, Robinson M, Rudolf MC. Weighing and measuring primary school children: evaluation of the TRENDS model for implementation of Department of Health guidelines. Child Care Health Dev. 2009;35(3):365-368.

16.Tadele N, Habta F, Akmel D, \& Deges E , "Knowledge, attitude and practice towards exclusive breastfeeding among lactating mothers in Mizan Aman town, Southwestern Ethiopia: descriptive cross-sectional study", International Breastfeeding Journal, 2016;11(3).

17.Shaker NZ, Hussein KA, Al-Azzawi SI , "Knowledge, Attitude and Practices (KAP) of Mothers toward Infant and Young Child Feeding in Primary Health Care (PHC) Centers, Erbil City", Kufa Journal for Nursing Sciences, 2012; 2 (2): 1-8.

18.El-Zanaty F and Ann AW, "Egypt Demographic and Health Survey EDHS 2014", Calverton, Maryland: Ministry of Health and Population ,Arab Republic of Egypt, El-Zanaty and Associates, and Macro International, 2014 ;p.157-185.

19.Khalaf Allah OS , "Assessment of Nutritional Status for Preschool Children (36 years)" (master thesis), faculty of medicine-Menoufiya University, Menoufeya-Egypt,2014.

20.Al-Binali AM , "Breastfeeding knowledge, attitude and practice among school teachers in Abha female educational district, southwestern Saudi Arabia", Int Breastfeed J., 2012;7(10).

21.El-Kishawi RR, Soo KL and Abed YA, "Anemia among children aged 2-5 years in the Gaza Strip- Palestinian: a cross sectional study", BioMedCentral Public Health,
2015;15 (P.319). Available at: http://bmcpublichealth.biomedcentral.com/ar ticles/10.1186/s12889-015-1652-2

22. Khassawneh M, Yousef Kh, Zouhair A \& Alkafajei , "Knowledge, Attitude and Practice of breastfeeding in the North of Jordan", International Breastfeeding Journal, 2006; 1(1): p.17.

23. Batal M, Boulghourjian C, Abdallah A \& Afifi R , "Breast-feeding and feeding practices of infants in a developing country: a national survey in Lebanon", Public Health Nutrition, 2005;9 (3) :313-319.

24.El-Sayed N, Al-Dossary HM \& Abdullah L, "Exclusive Breastfeeding, Prevalence and Maternal Concerns: Saudi and Egyptian Mothers", Journal of Education and Practice, 2016;7 (3): 5-11.

25.Egypt Nutrition Landscape Analysis Report, "The Nature and the Extent of Nutritional Challenges in Egypt", UNICEF Egypt Country Office and MoHP, CairoEgypt,2012. Available at:

26.https://www.unicef.org/mena/Landscape _ Anaylsis_Report_January_2013(1).pdf

27.Abu Hamad BA \& Sammour HK , "Weaning practices of mothers attending United Nations Relief and Works Agency health centers in the Gaza Governorates", Journal of Advanced Nursing, 2013;69: 773781.

28.UNICEF , "UNICEF Annual Results Report 2014- Our Story",2015. Available at: http://www.unicef.org/publications/files/UNI CEF_Annual_Report_2014_Web_07June15. pdf

29. Mahfouz EM, Mostafa S, Sadek RR, Hathout MH \& Awad Allah HI , "Rural/Urban infant nutrition gaps and KAP of mothers in El Minia and Giza governorate, Egypt", The Egyptian Journal of Community Medicine, 2003;21 (1): 17-24 .

30.Seedhom AE, Mohamed ES \& Mahfouz EM , "Determinants of stunting among preschool children, Minia, Egypt", International Public Health Forum, 2014;1 (2): 1-9.

31.Kleinman, R. E., "Pediatric Nutrition Handbook", (7th ed.), Editor in chief: Ronald 32.E. Kleinman, Elk Grove Village, IL: American Academy of Pediatrics. 2013; ISBN-13: 978-1- 